OPEN ACCESS

Edited by:

Yunlai Zhou,

Universidade Lusófona, Portugal

Reviewed by:

Enzo Martinelli,

University of Salerno, Italy

Pavlo Maruschak,

Ternopil Ivan Puluj National Technical

University, Ukraine

${ }^{*}$ Correspondence:

Chunyi Cui

cuichunyi@dlmu.edu.cn

Specialty section:

This article was submitted to

Structural Materials,

a section of the journal

Frontiers in Materials

Received: 20 May 2021

Accepted: 16 July 2021

Published: 23 August 2021

Citation:

Zhang $P$, Cui C, Li C, Zhang $C$ and

Liu H (2021) Holistic Design of Energy

Pile Bridge Deicing System With

Ontology-Based Multiobjective

Decision Making.

Front. Mater. 8:710404.

doi: 10.3389/fmats.2021.710404

\section{Holistic Design of Energy Pile Bridge Deicing System With Ontology-Based Multiobjective Decision Making}

\author{
Peng Zhang ${ }^{1}$, Chunyi Cui ${ }^{1 *}$, Chaoji $L^{1}{ }^{1}$, Cheng Zhang ${ }^{2}$ and Hailong Liu ${ }^{1}$ \\ ${ }^{1}$ Department of Civil Engineering, Dalian Maritime University, Dalian, China, ${ }^{2}$ Department of Civil Engineering, Xi'an Jiaotong- \\ Liverpool University, Suzhou, China
}

Even though the energy piles have been applied for the bridge deicing system, the traditional design approach is commonly a single-domain and objective-oriented method and is consequently lacking means to comprehensively consider all the relevant factors, such as life-cycle cost, investment payback cycle, carbon emissions, etc. This paper presents a holistic design scheme for the energy pile deicing system of bridge decks. In this paper, a holistic designing tool, namely, OntoBDDS, was developed based on ontology method and SWRL rules. It can automatically provide financial, safety, and heat flux information for designers to evaluate and optimize the design scheme of a deicing system in the early design stage of a bridge. After semantic and syntactical validation of the OntoBDDS system, a case study was also conducted to demonstrate how to leverage knowledge query to provide a series of design alternatives autonomously through considering different design parameters. This case study also verified the practicability and feasibility of the OntoBDDS holistic decision-making system and indicated its potential to be applied for other engineering problems when dealing with multiobjective holistic design making.

Keywords: ontology, holistic design, energy pile, deicing, bridge

\section{INTRODUCTION}

Snow and icing are serious hazards that may severely influence the safety and the normal operation of a transportation system. A slippery road surface may cause accidents (Lee et al., 2014) and huge maintenance costs. Taking the United States as an example, the annual expense of ice and snow removal is more than 2.3 billion US dollars, accounting for $20 \%$ of the US Department of Transportation (DOT) winter road maintenance budget (Han and Yu, 2017). Therefore, how to remove the ice and snow of bridge safely and effectively has become an important issue to ensure the safe and efficient running of the transportation system.

Traditionally, the snow and ice on the pavement can be removed physically or chemically. The physical method, by which the snow and ice are removed by specially designed vehicles or shovels, is a laborintensive yet low efficient method. The chemical methods also suffer from drawbacks such as corrosion to the bridge structure, pollution to the environment, and limited working scenario; most chemical ice removers are only effective below $3.9^{\circ} \mathrm{C}$ (Balbay and Esen, 2010). The energy pile system (Morino and Oka, 1994) provided another safe and efficient solution to the deicing problem. Figure 1 demonstrates the schematic of the energy pile-based deicing system (EPBDIS) for a bridge deck. It utilizes energy piles to extract geothermal heat from underground and then pumps the heat into the exchange tubes beneath the bridge deck for deicing. Compared with the traditional methods, the EPBDIS is labor-free and ecofriendly (Miyamoto and Takeuchi, 2005; Brandl, 2006), which makes it promising in field applications. 


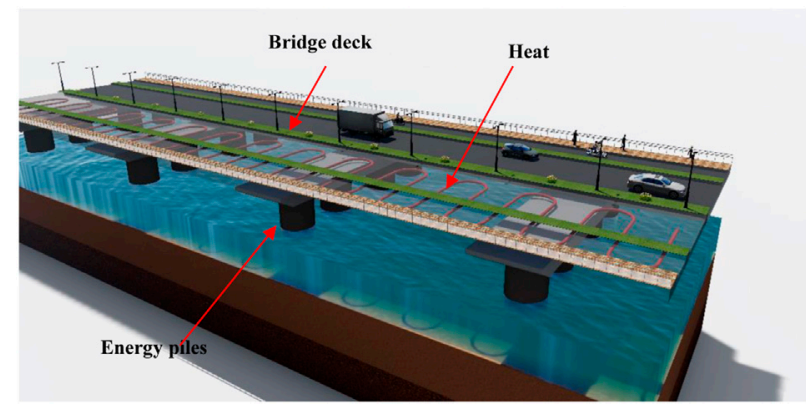

FIGURE 1 | The bridge deck deicing system using energy pile.

During the past decades, energy piles have been extensively studied theoretically and experimentally. In terms of thermal performance, a variety of numerical methods were proposed to study the heat transfer performance of the energy pile bridge deicing system and to verify its feasibility (Yari and Javani, 2010; Dupray et al., 2014; Han and Yu, 2017). Besides, many experimental studies and field tests were carried out to further validate the effectiveness of the energy piles. In Liu et al. (2007) and Balbay and Esen (2010), the authors conducted on-site experiments on the heat transfer performance of the energy pile bridge deck deicing system with a heat pump and verified its feasibility. Kong et al. (2019) and Bowers and Olgun (2015) studied and verified the thermal energy characteristics and feasibility of heat pump-free deicing systems based on field experiments. In addition, considering that the energy pile may cause temperature stress among the bridge structure, the influence of the energy pile on the bearing capacity was investigated by many researchers. In Laloui (2011) and Bourne-Webb et al. (2009), the effect of heat exchange on the bearing capacity of pile foundation was discussed. Subsequently, Amatya et al. (2012) and Ozudogru et al. (2015) discussed the response of energy pile`s thermal performance with different end constraints and ground conditions. Loveridge and Powrie (2013) and Jeong et al. (2014) identified the key factors affecting the thermal-mechanical interaction of energy piles.

An optimal design of the energy piles shall comprehensively consider every related aspect, including the thermal exchange efficiency, load capacity, finial cost, and environmental impacts. However, previous studies mainly focus on a specific aspect of the energy pile, neglecting the influence of other factors. For example, Nagai et al. (2009) developed a numerical simulation program to predict the temperature field of the system and evaluate the system performance. Liu et al. (2018) considered the heat transfer performance of the system and its economy and verified the feasibility of the system in Canada. In addition, due to the technical complexity of the ground source heat pump system, the relevant information is distorted and misunderstood when it is transmitted between different professions and departments, causing unnecessary losses (Zhang and Liao, 2015), which means that the rational use of systems requires an accurate and recognized domain of knowledge to ensure the accuracy of information transfer.
As a new semantic web technology, ontology can construct accurate domain knowledge and has been widely applied for knowledge sharing and exchange in different fields (Ahmed et al., 2007). Ontology's interdisciplinary features enable interrelated domains to be considered together, and its semantic structure, logical reasoning capabilities, and other characteristics provide an effective method for cross-domain integrated design. More importantly, its language could be recognized by both humans and computers. The ontology has been widely applied in relevant fields of energy pile bridge deicing systems such as pile engineering, bridge engineering, and ground source heat pump system. Specifically, Yurchyshyna and Zarli (2009) proposed a framework for consistency checking in buildings based on ontology. Zhang and Liao (2015) presented an ontology framework for describing ground source heat pump systems, providing guidance for constructing different ground source heat pump systems. Ren et al. (2019) proposed an ontology framework for bridge maintenance. The above provides the methodology and guidance for constructing the ontology framework of the energy pile bridge deck deicing system.

Based on the aforementioned works, it is necessary to use ontology to develop a designing tool for the energy pile bridge deck deicing system, which can comprehensively consider the heat flux, bearing capacity, and a total investment of the system to achieve optimal design. This research developed a comprehensive design decision-making tool named OntoBDDS (ontology of bridge deck deicing system using energy pile) for the holistic design of energy pile bridge deck deicing system in the early design stage. The remaining of the paper is organized as follows: Development of OntoBDDS for Multiobjective Holistic Design describes the development and validation of OntoBDDS; Case Study presents a case study to demonstrate how the engineers can use this tool to design the deicing system.

\section{DEVELOPMENT OF ONTOLOGY OF BRIDGE DECK DEICING SYSTEM FOR MULTIOBJECTIVE HOLISTIC DESIGN}

\section{Determination of the Primary Indicators for the Energy Pile-Based Bridge Deck Deicing System}

The key design parameters of the energy pile bridge deck deicing system include equipment cost, the vertical bearing capacity, heat flux, etc.

\section{The Equipment Cost}

The total cost of equipment and facilities includes the cost of the heat transfer tubes of the foundation and the deck and cost of the heat pumps. The cost of heat transfer tubes of the foundation can be calculated by the following equation:

$$
C^{\mathrm{PT}}=\sum_{i=1}^{n} C_{i}^{\mathrm{PT}} \times L_{i}^{\mathrm{PT}} \times N_{i}
$$


in which $i$ represents the $i^{\text {th }}$ type of pile; $L_{i}^{\mathrm{PT}}$ denotes the length of the $i^{\text {th }}$ type of pile; $C_{i}^{\mathrm{PT}}$ is the price of heat exchanger tube (RMB) per unit length of the $i^{\text {th }}$ pile type; $N_{i}$ is the number of the $i^{\text {th }}$ pile type.

The cost of the heat transfer tubes imbedded in the bridge deck is expressed as

$$
C^{\mathrm{BT}}=\sum_{j=1}^{n} C_{j}^{\mathrm{BT}} \times L_{j}^{\mathrm{BT}} \times N_{j}
$$

where $j$ represents the $j$ th type of bridge deck; $C_{j}^{\mathrm{BT}}$ is the price of the heat transfer tube per unit length; $L_{j}^{\mathrm{BT}}$ is the length of the heat transfer tube of the $j$ th type of bridge deck; $N_{j}$ is the number of the $j$ th type of bridge deck and $C^{\mathrm{BT}}$ is the total cost of the heat transfer tubes in the bridge deck.

The cost of the heat pumps can be easily attained by

$$
C^{\mathrm{P}}=\sum_{k=1}^{m} C_{k}^{\mathrm{P}} \times N_{k}^{\mathrm{P}}
$$

in which $k$ represents the $k$ th heat pump; $C_{k}^{\mathrm{P}}$ is the price of the $k$ th type of heat pump; $N_{k}^{\mathrm{P}}$ is the number of the $k$ th type of heat pump and $C^{\mathrm{P}}$ denotes the total cost of heat pump.

The total cost of equipment is expressed as

$$
C^{\mathrm{E}}=C^{\mathrm{PT}}+C^{\mathrm{BT}}+C^{\mathrm{P}}
$$

in which $C^{\mathrm{PT}}$ is the cost of the heat transfer tubes inside the foundation (in a unit of $\mathrm{RMB}$ ); $\mathrm{C}^{\mathrm{BT}}$ denotes the cost of the heat transfer tubs; $C^{\mathrm{P}}$ is the cost of the heat pumps and $C^{\mathrm{E}}$ is the total cost of all facilities.

\section{Heat Flux}

The heat extracted by the energy piles can be obtained by

$$
Q_{\text {source }}=\sum_{i=1}^{n} q_{i}^{\text {pile }} \times L_{i}^{\text {pile }} \times N_{i}
$$

where $i$ indicates the $i$ th type of pile; $q_{i}^{\text {pile }}$ denotes the heat attained by a unit length of the $i$ th type of pile; $L_{i}^{\text {pile }}$ is the length of the $i$ th type of pile; $N_{i}$ is the number of the $i$ th type of pile and $Q_{\text {source }}$ is the total heat extracted by energy piles.

According to Han and Yu (2017), the available heat for the deicing system can be calculated by

$$
Q_{\text {heat }}=\frac{C O P}{C O P-1} \times Q_{\text {source }}
$$

in which $C O P$ is the coefficient of performance of the heat pumps (Self et al., 2013), $Q_{\text {source }}$ is the total energy extracted by energy piles from underground; $Q_{\text {heat }}$ is the heat available for deicing.

The heated area of the bridge deck is expressed as

$$
A_{\text {heat }}=\sum_{j=1}^{n} a_{j}^{\text {heat }} \times N_{j}
$$

where $j$ represents the $j$ th type of bridge deck; $a_{j}^{\text {heat }}$ is the area of $j$ th type bridge deck heated by energy pile deicing system; $N_{j}$ 为 is the number of $j$ th type bridge deck and $A_{\text {heat }}$ denotes the total area heated by the deicing system.
Therefore, the heat flux of the bridge deck without an additional heat pump is

$$
q=\frac{Q_{\text {source }}}{\mathrm{A}_{\text {heat }}}
$$

where $Q_{\text {source }}$ is the total energy; $A_{\text {heat }}$ is the heated area and $q$ is the heat flux provided by the energy pile system without a heat pump.

Similarly, the heat flux of the bridge deck with a heat pump is as follows:

$$
q_{\text {pump }}=\frac{Q_{\text {heat }}}{\mathrm{A}_{\text {heat }}}
$$

where $Q_{\text {heat }}$ is the total heat provided by the deicing system; $A_{\text {heat }}$ is the heated area and $q_{\text {pump }}$ represents the heat flux of the deicing system with heat pump.

\section{Vertical Bearing Capacity}

The bearing capacity provided by the energy piles can be obtained by

$$
Q=\sum_{i=1}^{n} \frac{Q_{i}^{\mathrm{vk}}}{K} \times N_{i}
$$

in which $i$ is the $i$ th type file; $Q_{i}^{\mathrm{vk}}$ is the vertical bearing capacity of the $i$ th type file; $K$ is a safety factor; $N_{i}$ is the number of the $i$ th type file and $\mathrm{Q}$ denotes the total vertical bearing capacity.

\section{Evaluation}

The evaluation of a deicing system is conducted via a comparison between provided heat flux and required heat flux $q_{0}$. Grades and criteria are listed in Table $\mathbf{1}$.

\section{Design and Development of Ontology of Bridge Deck Deicing System The System Framework and User Guides of Ontology of Bridge Deck Deicing System}

The proposed designing tool, OntoBDDS, consists of four major components: the database, the management system of ontologies, the editing system of rules, and the querying interface, as illustrated in Figure 2. Of these four parts, the database provides a foundation of all functions. All data and ontologies of the energy piles and information of the deicing system are saved in the database in OWL (ontology web language) format. The management system of ontologies is the core part of OntoBDDS, and in this study, it is developed by Protégé 5.2. The editing system of rules can offer a reasoning function with SWRL (sematic web rule language), to realize the holistic design of energy pile deicing system. Moreover, engineers can use the querying interface to obtain feasible solutions to the designing problem. The essential components of the ontology system, OntoBDDS, are specified as follows:

\section{Ontology editor}

Protégé-OWL 5.2 provides a platform to create and update ontologies, which is compatible with most OWL files and has various plug-ins for a user to select. 
TABLE 1 | The evaluation of the energy pile deicing system for bridge deck.

\begin{tabular}{lll} 
Evaluation & Expression & \multicolumn{1}{c}{ Description } \\
\hline Good & $q \geq q_{0}$ & The energy pile deicing system can satisfy the heat flux requirement without a heat pump \\
Feasible & $q_{\text {pump }} \geq q_{0} \geq q$ & The energy pile deicing system can satisfy the heat flux requirement with a heat pump \\
Not feasible & $q_{0}>q_{\text {pump }}$ & The energy pile deicing system cannot satisfy the heat flux requirement
\end{tabular}

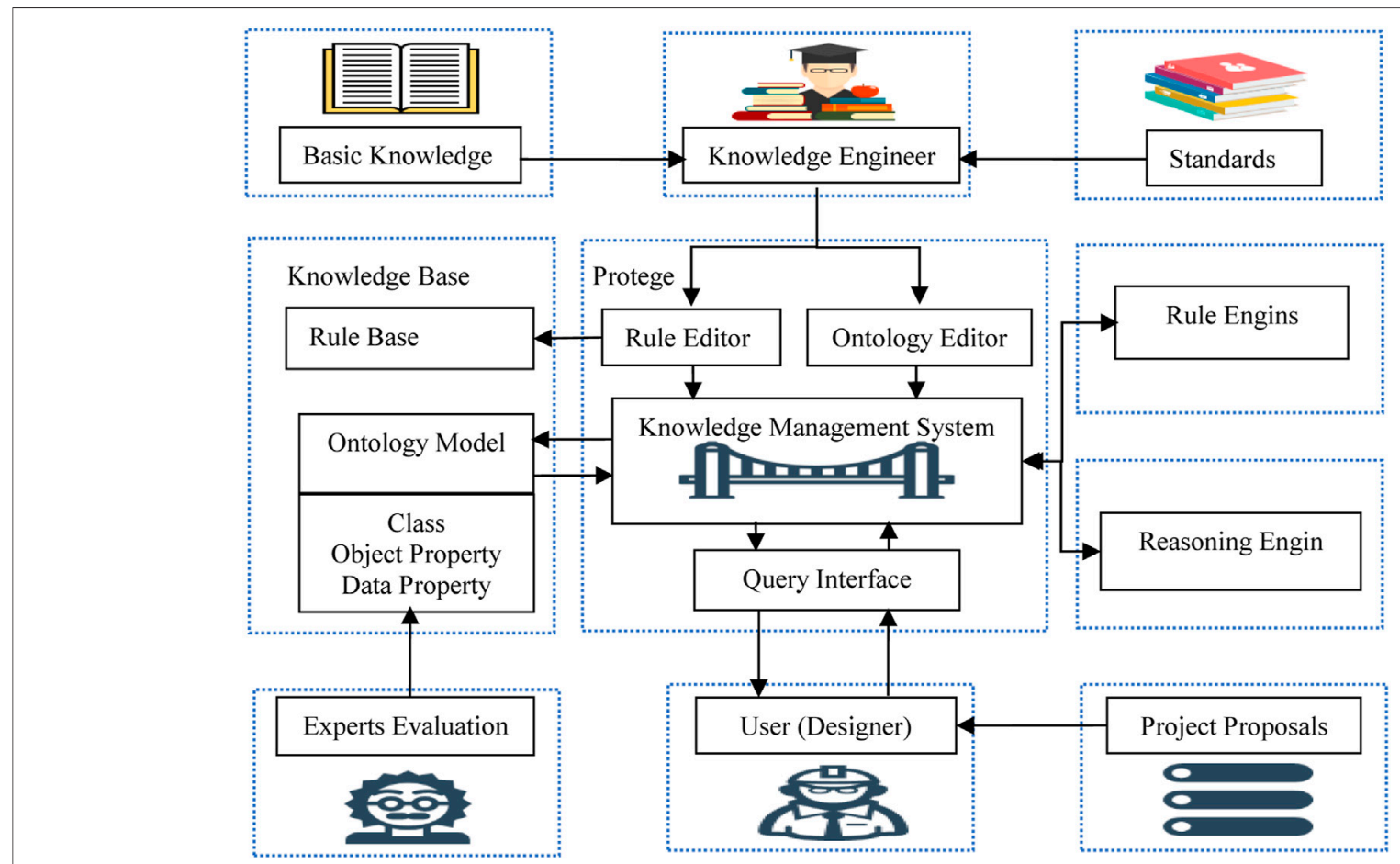

FIGURE 2 | The developed framework of OntoBDDS.

\section{Ontology reasoner}

Pellet is an OWL reasoning engine that implements the services of basic reasoning and consistency checking for OWL ontologies.

\section{Plug-ins}

SWRLTab is a Protégé-OWL plug-in that edits the SWRL rules, while SQWRLTab is a plug-in that edits SQWRL rules for querying.

Based on OntoBDDS, engineers can conduct a holistic design of the energy pile deicing system following the process illustrated in Figure 3.

\section{The Development of the Ontology of Bridge Deck Deicing System}

The establishment of the OntoBDDS follows three major steps: Knowledge Identification, Knowledge Specification, and Knowledge Refinement. In the Knowledge Identification, the scope and the aim of the energy pile-based deicing system were determined on the basis of the function of the
OntoBDDS and ontology models established previously. In the step of Knowledge Specification, a specification of the knowledge model is constructed by establishing a semiformed ontology model, which can be further refined by engineers according to their designing purpose. In the last step, the Knowledge Refinement step, the ontology model is validated and refined to reassure the accuracy and conciseness of the system.

In this study, the scope of the ontology model includes pile foundation engineering, bridge engineering, bridge deicing, and geothermal pump system. Heat flux, cost, and safety of the bridge structure are the major issues to be considered in holistic design. The key concepts and terms of the OntoBDDS follow the IFC standard and relative ontology models established previously (Ren et al., 2019). The key concepts and terms are shown in Figure 4 using UML (Unified Modeling Language).

In this study, the Ontology Development 101 (Noy and Mcguinness, 2001) is utilized to develop the OntoBDDS. The Ontology Development 101 is a methodology widely accepted for establishing ontology systems because of its efficiency and simplicity. The detailed steps are illustrated in Figure 5. It can be further explained as follows: 


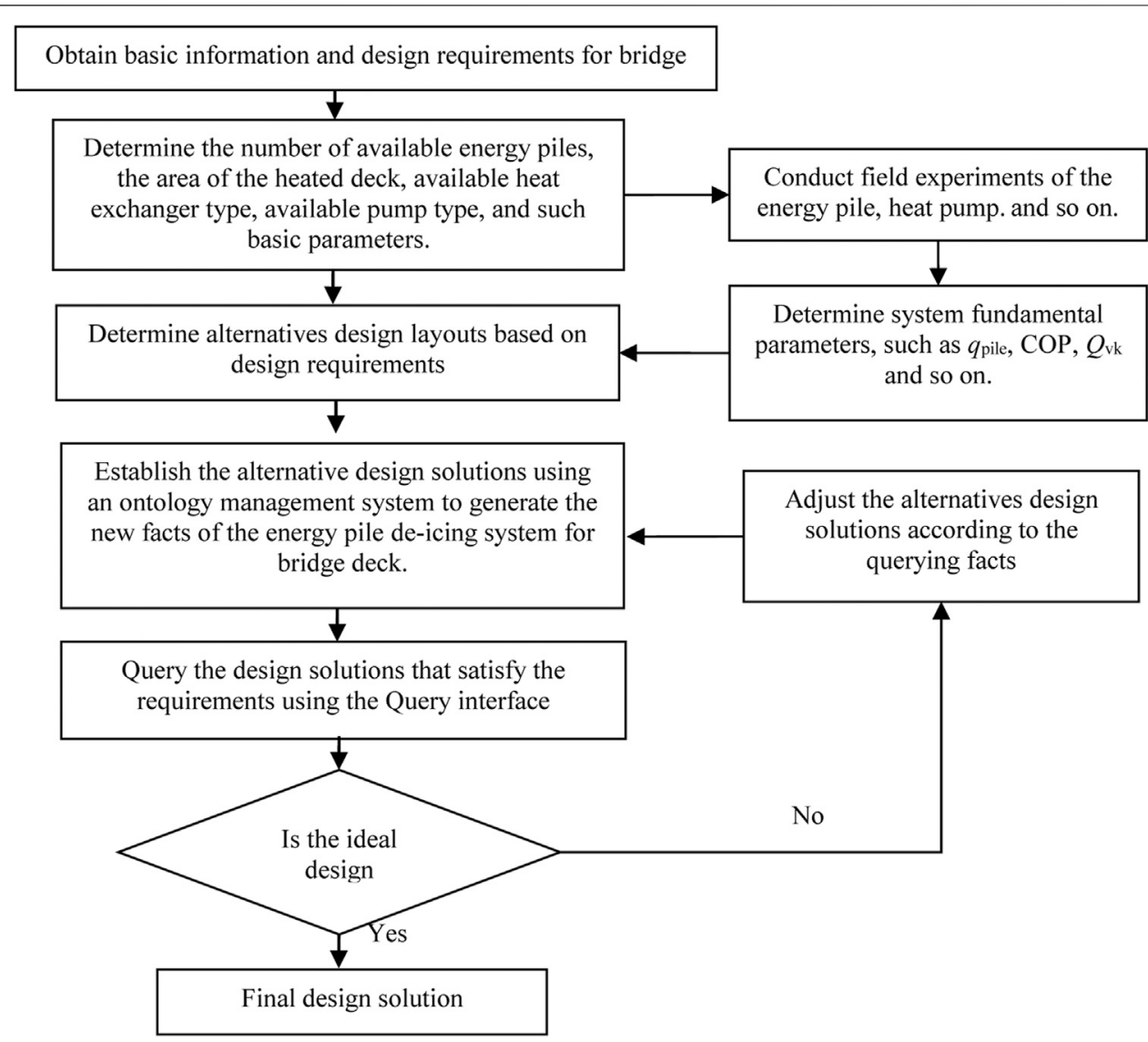

FIGURE 3 | The design flow chart of energy pile deicing system for bridge deck using OntoBDDS.

Step 1: The relevant domain and scope of the ontology are determined based on basic questions (BQ) and competency questions (CQ).

Step 2: IFC framework of the building SMART is adopted as the main development standard for the exchanging and sharing of Building Information, which facilitates the concept development of information ontologies for the holistic design of energy pile system (Horrocks et al., 2004).

Step 3: A dictionary of key concepts and terms regarding the deicing systems is established, which includes maintenance, safety, financial cost, mechanical property, etc.

Step 4: According to the dictionary established in Step 3, general classes of the OntoBDDS are established as shown in Figure 6A.

Step 5: There are mainly two types of properties to describe the relevant classes, namely, object properties and data properties, which define the relationships between classes and represent the characteristics of class instances, respectively, as illustrated in Figures 6B,C.

Step 6: In this step, specific instances are created. Each instance represents a unique design solution of the energy pile-based deicing system.
Step 7: SWRL rules for the holistic design of energy pile system are defined to improve the ontology's flexibility for calculating and reasoning. There are four types of atoms for SWRL rules, i.e., Class atoms, Individual Property atoms, Data Valued Property atoms, and Built-in atoms. In addition, the symbols of SWRL rules include the connection symbol "', the implication symbol ' $\rightarrow$ ', and the question mark' ?' (Guizzardi et al., 2008). The specific SWRL rules for the calculation of equipment cost of energy pile system is illustrated as follows:

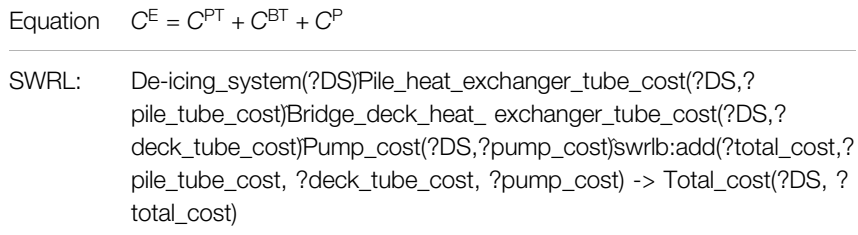

Step 8: User can query design solutions by inputting SQWRL rules in SQWRLQueryTab of the Protégé query interface. An example of cost query for energy pile system is illustrated as follows: 
SQWRL De-icing_system(?DS)Total_cost(?DS,?total_cost)Q(?DS,? bearing_capacity)'qO(?DS,?q_O) q(?DS,?q_)'q_pump(?DS,? q_heat_pump)Evaluation(?DS,?evaluation)'has_pump(?DS, ? pump_type)->sqwrl:select(?DS,?total_cost,?bearing_capacity,? pump_type,?q_0,?q_,?q_heat_pump,?evaluation) compare the ontology model with existing models, while the other method is to establish a new ontology model by expanding the existing one (Green et al., 2002). In this study, the OntoBDDS is developed based on IFC and existing ontology models (Ren et al., 2019). Therefore, the semantic

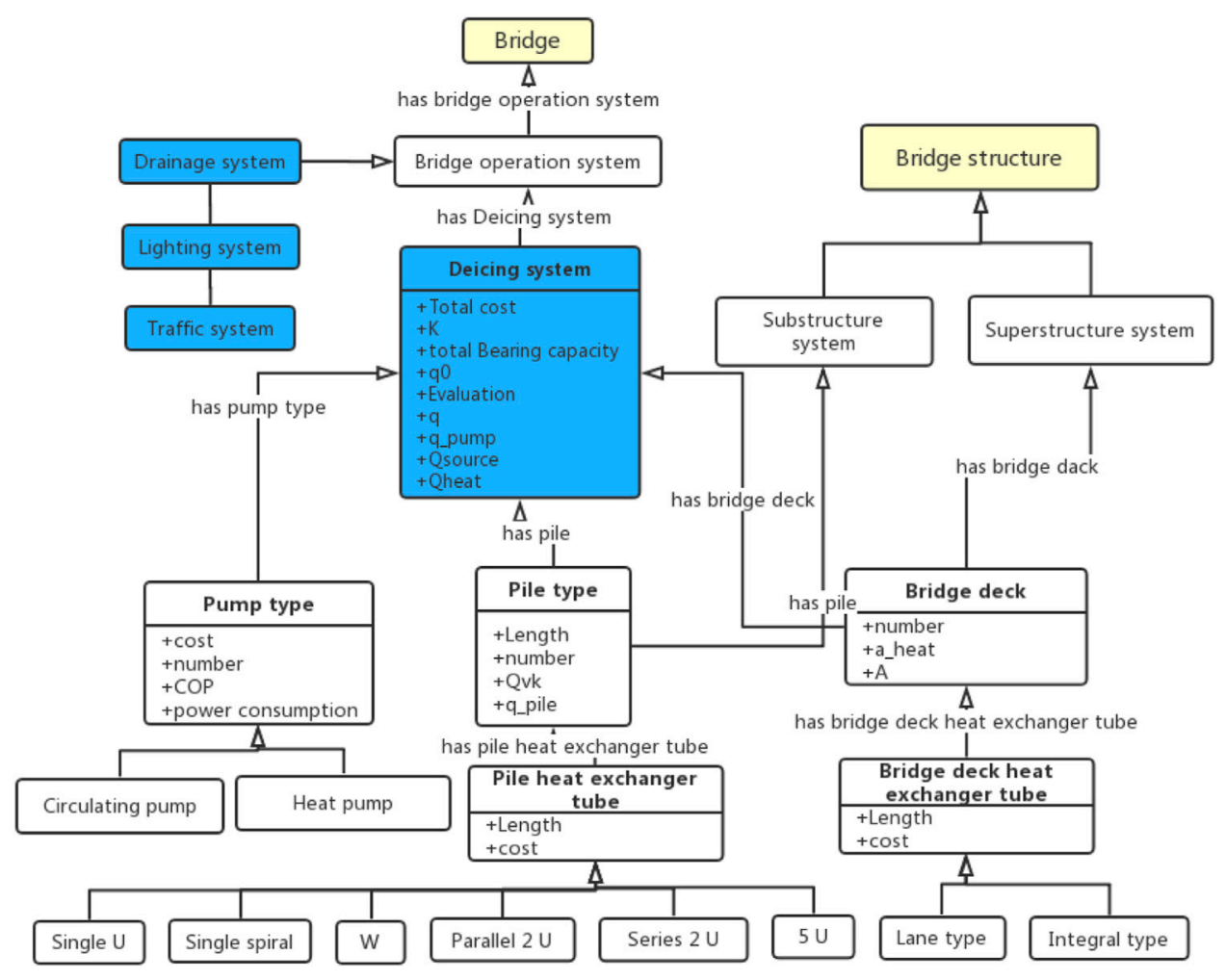

FIGURE 4 | Flowchart of UML classes for the key concepts of OntoBDDS ontology.

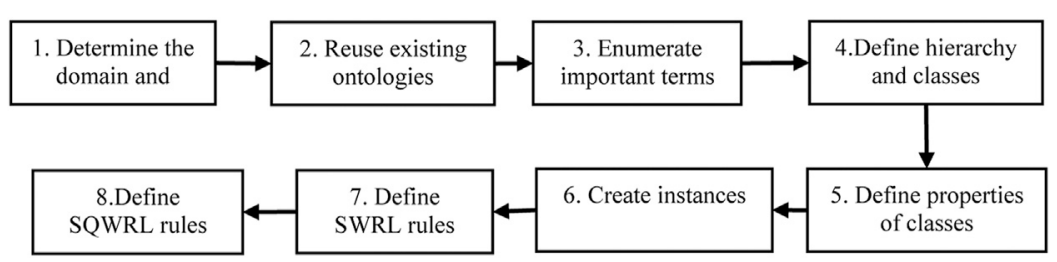

FIGURE 5 | Eight-step methodology.

\section{Ontology Validation}

Validation of the OntoBDDS system was performed to assure its accuracy and ability to provide the expected design function. The validation includes semantic correctness, syntactic correctness, and rules validation.

\section{Semantic Validation}

There are two methodologies to assure the semantic correctness of an ontology model. One method is to correctness of the key concepts and terms is automatically validated.

\section{Syntactical Validation}

Syntactical validation can be conducted by reasoning engines. In this study, the OntoBDDS is developed using Protégé-OWL 5.2. The pellet reasoner embedded in Protégé-OWL 5.2 can be used to detect syntactical errors of OntoBDDS. Figure 7 shows the log of running pellet plug-in for completed consistency checking of the OntoEPS. 


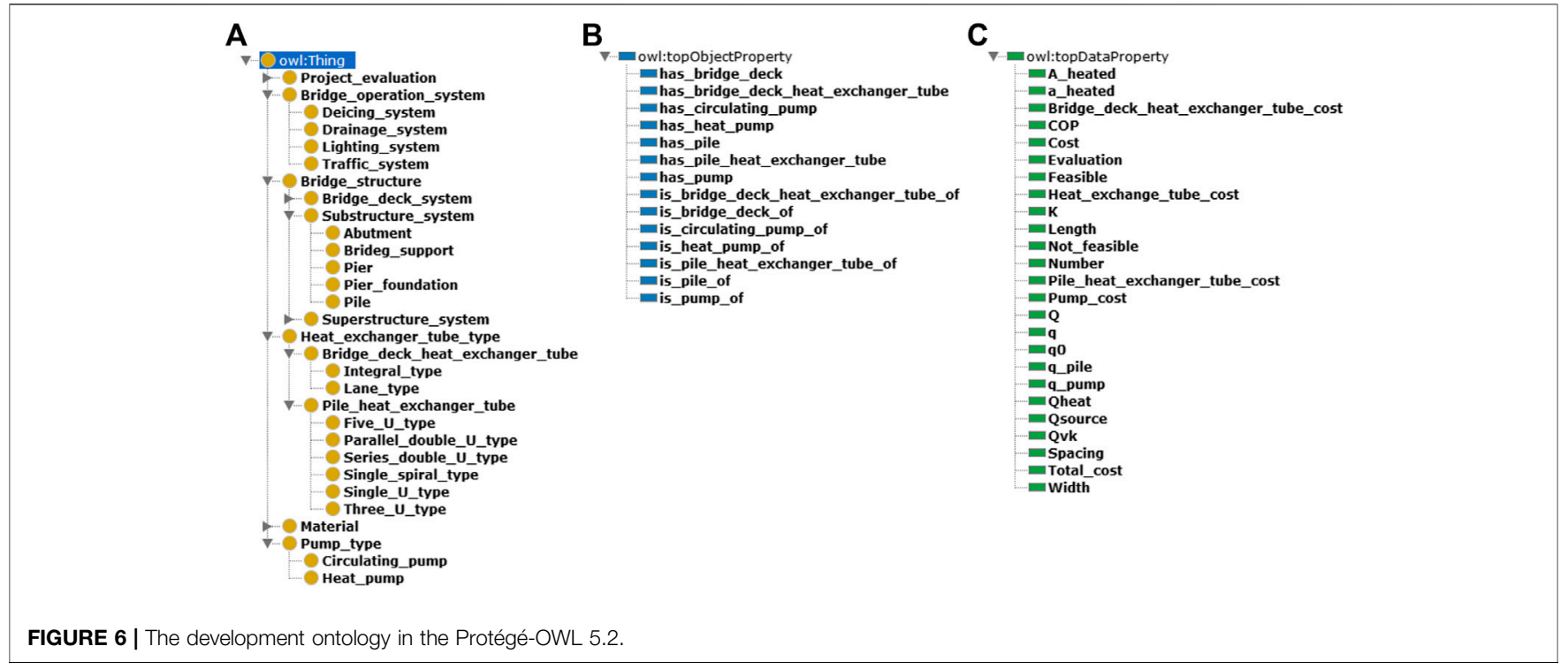

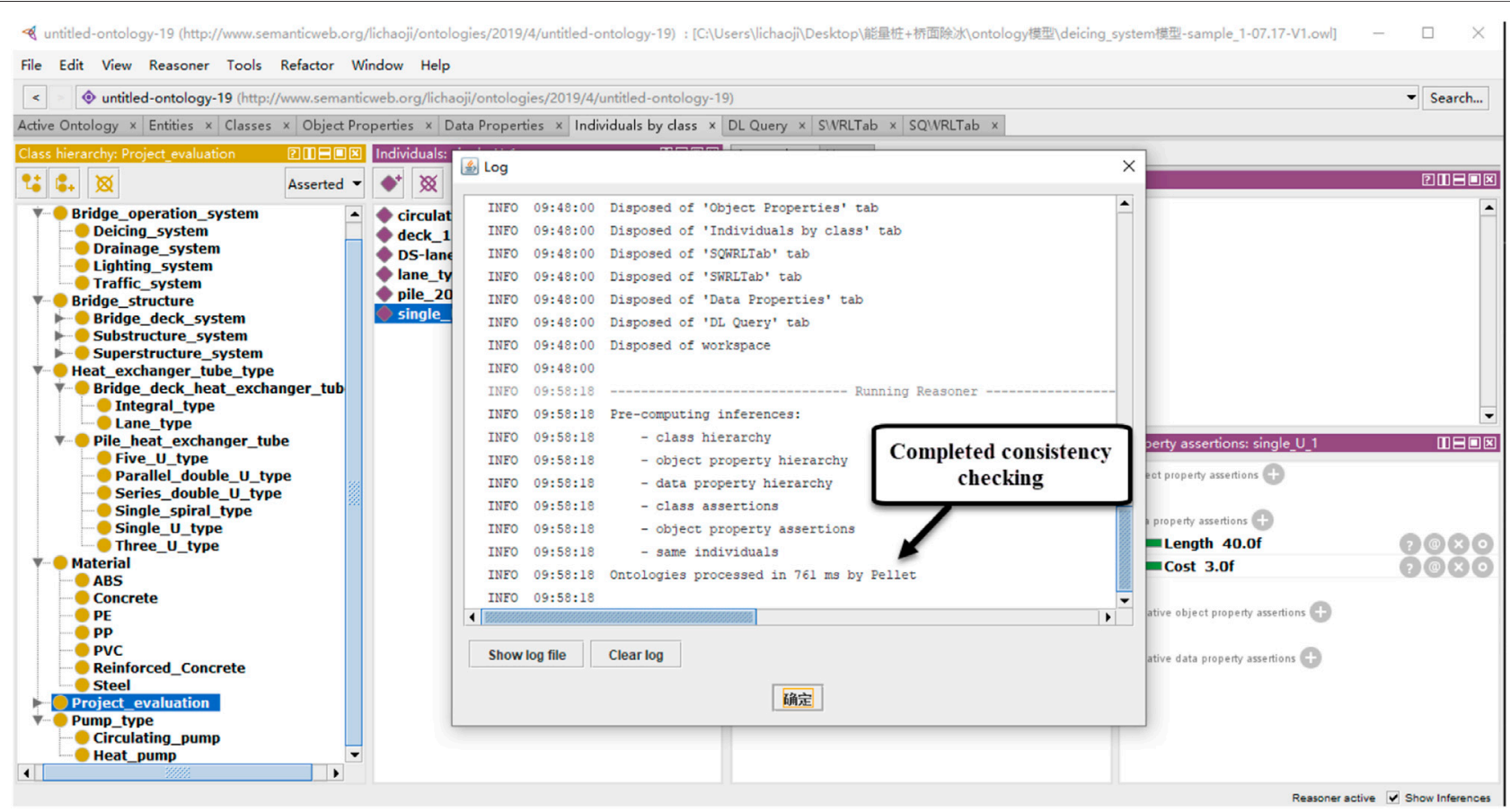

FIGURE 7 | The log of running pellet plug-in for completed consistency checking of the OntoBDDS.

\section{Rules Validation}

In this study, a plug-in called SWRLTAB is utilized to validate the rules preliminarily, as shown in Figure 8.
Then, in Case Study, a case study will be presented to further verify the effectiveness and feasibility of all the rules of OntoBDDS. 


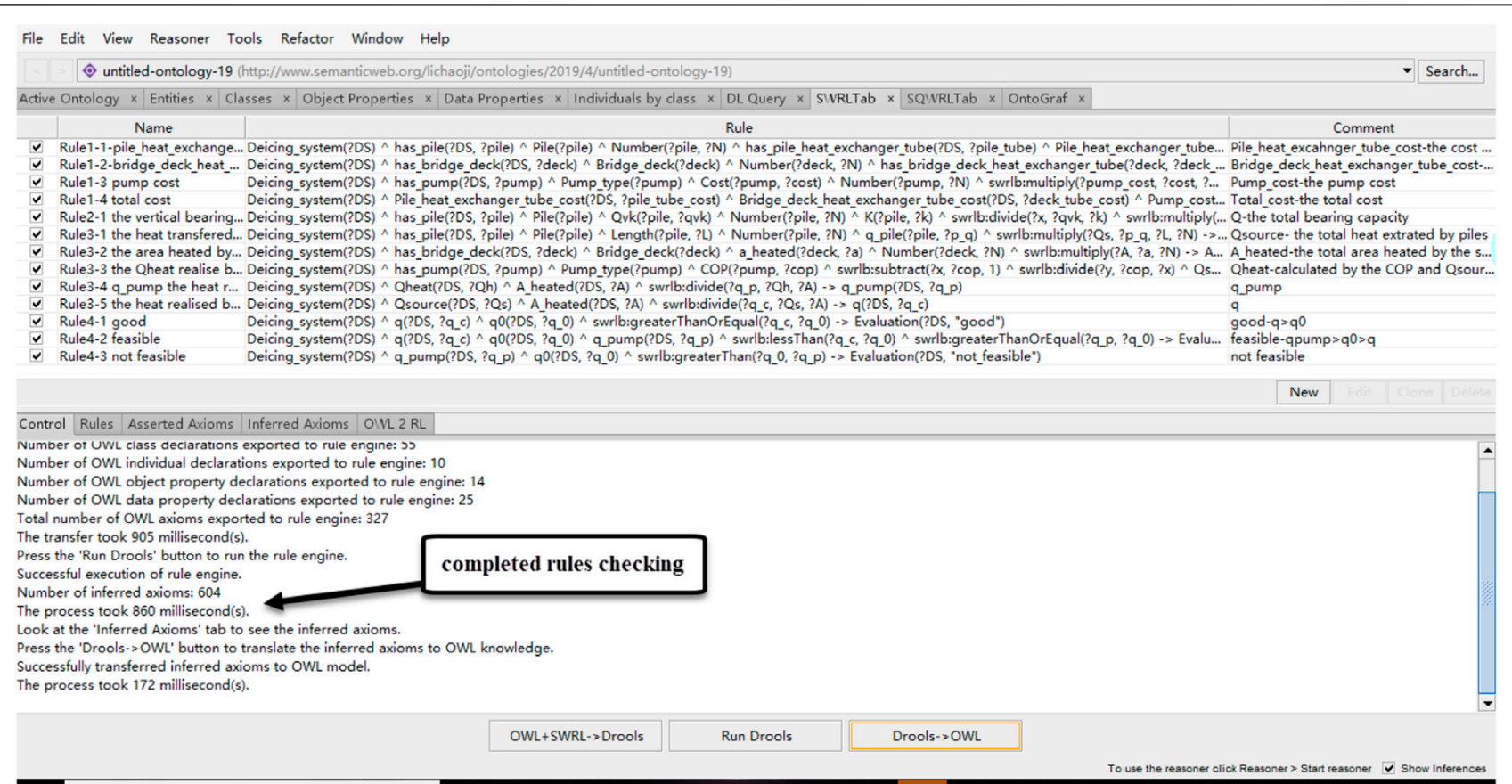

FIGURE 8 | The log of running SWRLTab plug-in for the SWRL rules validation.

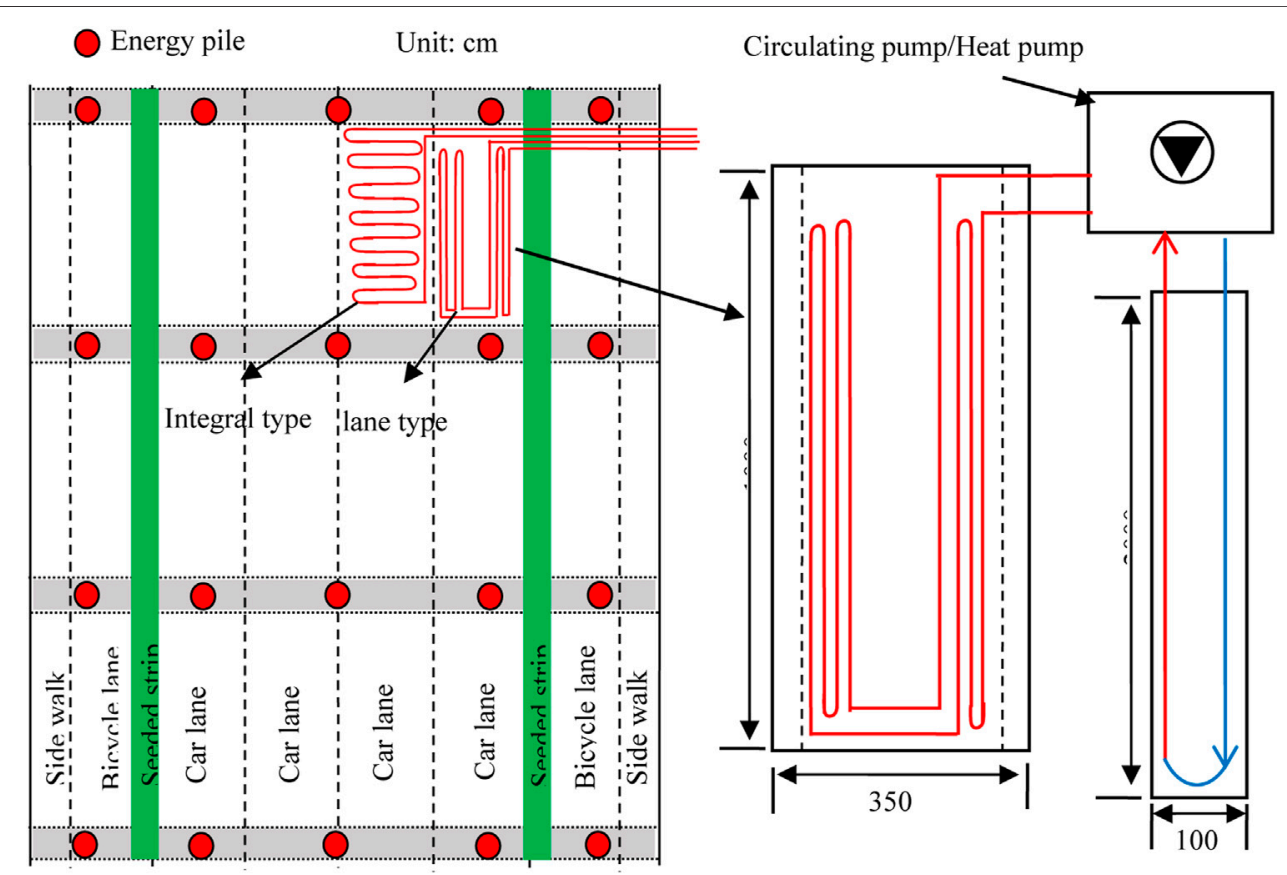

FIGURE 9 | Basic information of the bridge for energy pile-based bridge deck deicing system.

\section{CASE STUDY}

\section{Case Study Description}

In this section, an energy pile-based deicing system for a bridge deck is designed to demonstrate the main functions of the
OntoBDDS software. The prototype bridge is a three-span beam bridge constructed in Jiangyin of Jiangsu Province. Its configuration is illustrated in Figure 9.

As shown in Figure 9, the size of the bridge deck allows for no more than 20 energy piles to be constructed. Moreover, heat 
TABLE 2 | The detail of the design solution.

\begin{tabular}{|c|c|c|c|c|c|c|c|c|c|c|c|c|c|c|}
\hline \multirow{2}{*}{$\begin{array}{l}\text { Design } \\
\text { solutions }\end{array}$} & \multicolumn{2}{|c|}{ Pile } & \multicolumn{4}{|c|}{ Pump } & \multicolumn{2}{|c|}{ Bridge deck } & \multicolumn{3}{|c|}{ Pile heat exchanger tube } & \multicolumn{3}{|c|}{ Bridge deck heat exchange tube } \\
\hline & $\begin{array}{c}q_{\text {pile }} \\
(w / m)\end{array}$ & $\begin{array}{l}Q_{\mathrm{vk}} \\
(\mathbf{k N})\end{array}$ & Type & COP & $\begin{array}{l}\text { Cost } \\
\text { (RMB) }\end{array}$ & Number & $A\left(m^{2}\right)$ & Number & Type & Length (m) & $\begin{array}{l}\text { Cost } \\
\text { (RMB) }\end{array}$ & Type & Length (m) & $\begin{array}{c}\text { Cost } \\
\text { (RMB) }\end{array}$ \\
\hline DS-lane-single_U & 27 & 6,500 & $\begin{array}{l}\text { Circulating } \\
\text { pump }\end{array}$ & -- & 2,800 & 1 & 15 & 12 & Single U & 40 & 3 & Lane type & 90 & 3 \\
\hline $\begin{array}{l}\text { DS-lane-single_U-heat } \\
\text { pump }\end{array}$ & 27 & 6,500 & Heat pump & 3 & 16,000 & 1 & 15 & 12 & Single $U$ & 40 & 3 & Lane type & 90 & 3 \\
\hline DS-lane-P_2_U & 31.5 & 6,430 & $\begin{array}{l}\text { Circulating } \\
\text { pump }\end{array}$ & --- & 2,800 & 1 & 15 & 12 & Parallel $2 \mathrm{U}$ & 80 & 3 & Lane type & 90 & 3 \\
\hline $\begin{array}{l}\text { DS-integral-P_2_U- } \\
\text { heat_pump }\end{array}$ & 31.5 & 6,430 & Heat pump & 3 & 16,000 & 1 & 30 & 12 & Parallel $2 \mathrm{U}$ & 80 & 3 & $\begin{array}{l}\text { Integral } \\
\text { type }\end{array}$ & 150 & 3 \\
\hline DS-integral-S_2_U & 36 & 6,400 & $\begin{array}{l}\text { Circulating } \\
\text { pump }\end{array}$ & --- & 2,800 & 1 & 30 & 12 & Series $2 U$ & 80 & 3 & $\begin{array}{l}\text { Integral } \\
\text { type }\end{array}$ & 150 & 3 \\
\hline $\begin{array}{l}\text { DS-integral-S_2_U- } \\
\text { heat_pump }\end{array}$ & 36 & 6,400 & Heat pump & 3 & 16,000 & 1 & 30 & 12 & Series $2 U$ & 80 & 3 & $\begin{array}{l}\text { Integral } \\
\text { type }\end{array}$ & 150 & 3 \\
\hline DS-integral-3_U & 45 & 6,300 & $\begin{array}{l}\text { Circulating } \\
\text { pump }\end{array}$ & --- & 2,800 & 1 & 30 & 12 & $3 U$ & 120 & 3 & $\begin{array}{l}\text { Integral } \\
\text { type }\end{array}$ & 150 & 3 \\
\hline $\begin{array}{l}\text { DS-integral-3_U- } \\
\text { heat_pump }\end{array}$ & 45 & 6,300 & Heat pump & 3 & 16,000 & 1 & 30 & 12 & $3 U$ & 120 & 3 & $\begin{array}{l}\text { Integral } \\
\text { type }\end{array}$ & 150 & 3 \\
\hline DS-lane-5_U & 54 & 6,250 & $\begin{array}{l}\text { Circulating } \\
\text { pump }\end{array}$ & --- & 2,800 & 1 & 15 & 12 & $5 U$ & 200 & 3 & $\begin{array}{l}\text { Integral } \\
\text { type }\end{array}$ & 150 & 3 \\
\hline $\begin{array}{l}\text { DS-integral-5_U- } \\
\text { heat_pump }\end{array}$ & 54 & 6,250 & Heat pump & 3 & 16,000 & 1 & 30 & 12 & $5 U$ & 200 & 3 & Lane type & 90 & 3 \\
\hline DS-integral-spiral & 63 & 6,200 & $\begin{array}{l}\text { Circulating } \\
\text { pump }\end{array}$ & --- & 2,800 & 1 & 30 & 12 & $\begin{array}{l}\text { Single } \\
\text { spiral }\end{array}$ & 250 & 3 & $\begin{array}{l}\text { Integral } \\
\text { type }\end{array}$ & 150 & 3 \\
\hline $\begin{array}{l}\text { DS-integral-spiral- } \\
\text { heat_pump }\end{array}$ & 63 & 6,200 & Heat pump & 3 & 16,000 & 1 & 30 & 12 & $\begin{array}{l}\text { Single } \\
\text { spiral }\end{array}$ & 250 & 3 & $\begin{array}{l}\text { Integral } \\
\text { type }\end{array}$ & 150 & 3 \\
\hline
\end{tabular}

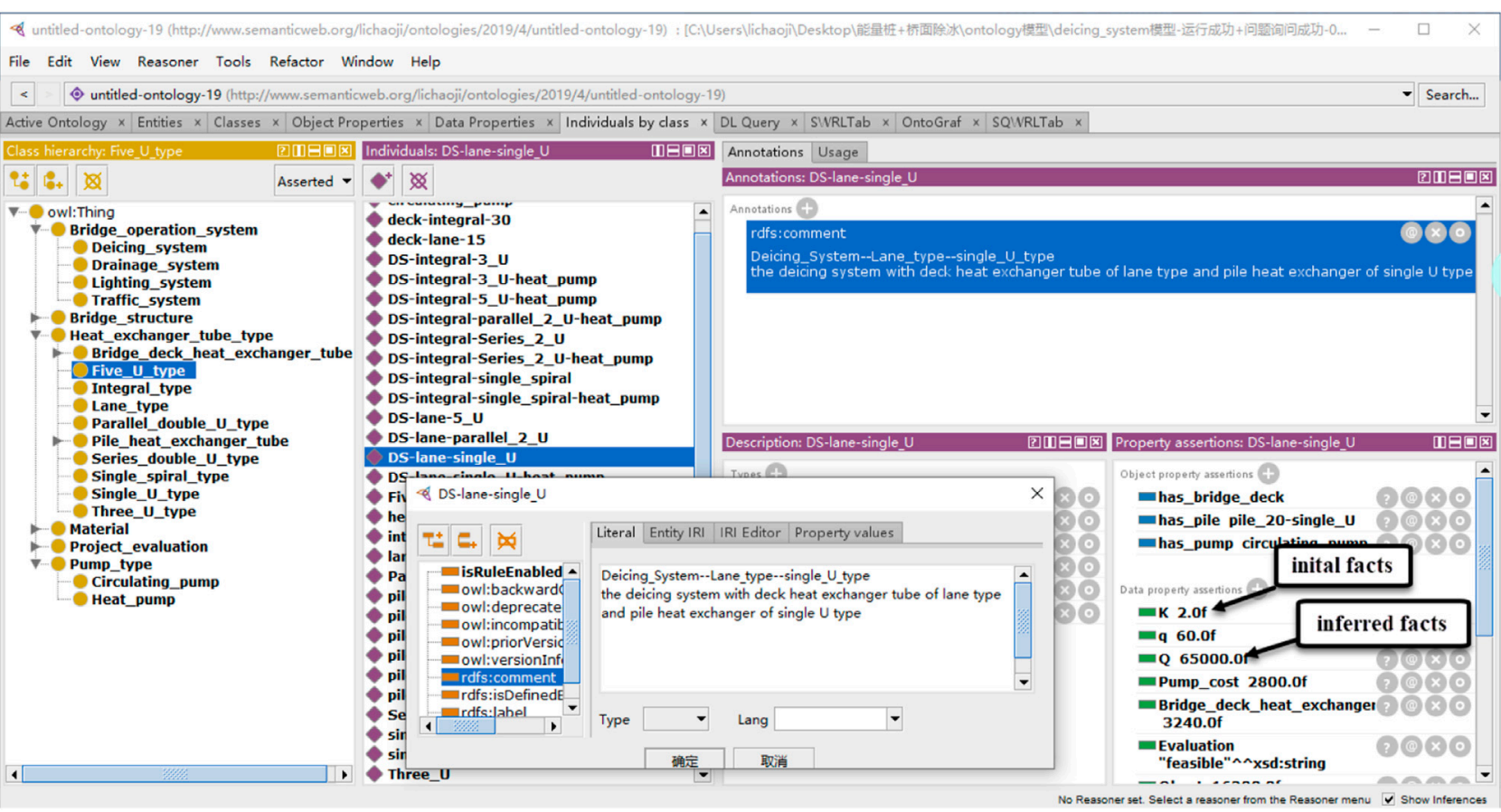

FIGURE 10 | Inferred facts after running the OntoBDDS.

TABLE 3 | SWRL rules to calculate bearing capacity.

Rule 1

Calculating the bearing capacity: $Q=\sum_{i=1}^{n} \frac{Q_{i}^{\prime k}}{K} \times N_{i}$

De-icing_system(?DS)has_pile(?DS, ?pile)^Pile(?pile)^Q Qvk(?pile, ?qvk)^Number(?pile, ?N)^K(?DS, ?k)^swrlb:divide(?x, ?qvk, ?k) ^swrlb:multiply(?Q0, ?x, ?N) -> Q(?DS, ?QO) 
TABLE 4 | SWRL rules to calculate the total cost.

Rule 1

Calculating pile heat exchanger tube cost: $C^{\mathrm{PT}}=\sum_{i=1}^{n} C_{i}^{\mathrm{PT}} \times L_{i}^{\mathrm{PT}} \times N_{i}$

De-icing_system(?DS)has_pile(?DS,?pile)Pile(?pile)Number(?pile,?N)has_pile_heat_exchanger_tube(?pile,?pile_tube) Pile_heat_exchanger_tube(?pile_tube)Cost(?pile_tube,?cost) Length(?pile_tube,?L)swrlb:multiply(?pile_tube_cost,?cost,?L,?N)->Pile_heat_exchanger_tube_cost(?DS,? pile_tube_cost)

Rule 2

Calculating bridge deck heat exchanger tube cost: $C^{\mathrm{BT}}=\sum_{j=1}^{n} C_{j}^{\mathrm{BT}} \times L_{j}^{\mathrm{BT}} \times N_{j}$

De-icing_system(?DS)has_bridge_deck(?DS, ?deck)^Bridge_deck(?deck)^Number(?deck, ?N) has_bridge_deck_heat_exchanger_tube(?deck,?deck_tube)Bridge_deck_heat_exchanger_tube(?deck_tube)Cost(? deck_tube,?cost)^ Length(?deck_tube, ?L)^swrlb:multiply(?deck_tube_cost, ?N,

?L, ?cost) -> Bridge_deck_heat_exchanger_tube_cost(?DS, ?deck_tube_cost)

Rule 3

Calculating pump cost: $C^{\mathrm{P}}=\sum_{k=1}^{m} C_{k}^{\mathrm{P}} \times N_{k}^{\mathrm{P}}$

De-icing_system(?DS) ^ has_pump(?DS, ?pump)^ Pump_type(?pump)^Cost(?pump, ?cost)^Number(?pump, ?N)^ swrlb: multiply(?pump_cost, ?cost, ?N) -> Pump_cost(?DS, ?pump_cost)

Rule 4

Calculating total cost: $C^{\mathrm{E}}=C^{\mathrm{PT}}+C^{\mathrm{BT}}+C^{\mathrm{P}}$

De-icing_system(?DS)Pile_heat_exchanger_tube_cost(?DS, ?pile_tube_cost)Bridge_deck_heat_exchanger_tube_cost(?

DS,?deck_tube_cost)Pump_cost(?DS,?pump_cost)'swrlb:add(?total_cost, ?pile_tube_cost, ?deck_tube_cost, ?

pump_cost) -> Total_cost(?DS, ?total_cost)

TABLE 5 | SWRL rules to calculate heat flux.

Rule 1

Calculating the heat transferred by the energy pile: $Q_{\text {source }}=\sum_{i=1}^{n} q_{i}^{\text {pile }} \times L_{i}^{\text {pile }} \times N_{i}$

De-icing_system(?DS) has_pile(?DS, ?pile)^Pile(?pile)^Length(?pile, ?L)^Number(?pile, ?N)^ q_pile(?pile, ?p_q)^swrlb: multiply(?Qs, ?p_q, ?L, ?N) -> Qsource(?DS, ?Qs)

Rule 2

Calculating the heat provided by heat pump: $Q_{\text {heat }}=\frac{C O P}{C O P-1} \times Q_{\text {source }}$

De-icing_system(?DS)has_pump(?DS, ?pump)^Pump_type(?pump) ^ COP(?pump, ?cop)^swrlb:subtract(?x, ?cop, 1)^

swrlb:divide(?y, ?cop, ?x)^Qsource(?DS, ?Qs)^swrlb:multiply(?Qh, ?y, ?Qs) -> Qheat(?DS, ?Qh)

Rule 3

Calculating the area heated by the system: $A_{\text {heat }}=\sum_{j=1}^{n} a_{j}^{\text {heat }} \times N_{j}$

De-icing_system(?DS)has_bridge_deck(?DS, ?deck)^Bridge_deck(?deck)^a_heated(?deck, ?a)^Number(?deck, ?N)^swrlb: multiply(?A, ?a, ?N) -> A_heated(?DS, ?A)

Rule 4

Calculating the heat flux without heat pump: $q=\frac{Q_{\text {source }}}{A_{\text {hest }}}$

De-icing_system(?DS)^Qsource(?DS, ?Qs)^A_heated(?DS, ?A)^swrlb:divide(?q_c, ?Qs, ?A) -> q(?DS, ?q_c)

Rule 5

Calculating the heat flux with heat pump: $q_{\text {pump }}=\frac{Q_{\text {heat }}}{A_{\text {heat }}}$

De-icing_system(?DS) ^Qheat(?DS, ?Qh)^A_heated(?DS, ?A)^ swrlb:divide(?q_p, ?Qh, ?A) -> q_pump(?DS, ?q_p)

TABLE 6 | SWRL rules for evaluation.

Rule 1

Rule 2

Rule 3
Evaluation: good

De-icing_system(?DS)q(?DS,?q_c)q0(?DS,?q_0)swrlb:greaterThanOrEqual(?q_c, ?q_0) -> Evaluation(?DS, "good")

Evaluation: feasible

De-icing_system(?DS)q(?DS,?q_c)qO(?DS,?q_0)q_pump(?DS,?q_p)'swrlb:lessThan (?q_c, ?q_0)^ swrlb: greaterThanOrEqual(?q_p, ?q_0) -> Evaluation(?DS, "feasible")

Evaluation: not feasible

De-icing_system(?DS) ^q_pump(?DS, ?q_p)^qO(?DS, ?q_0)^swrlb:greaterThan(?q_0, ?q_p) -> Evaluation(?DS,

"not_feasible")

TABLE 7 | SQWRL rules to query total cost, bearing capacity, q0, qpump, and evaluation.

SQWRL

De-icing_system(?DS)^ Total_cost(?DS, ?total_cost)^Q(?DS, ?bearing_capacity) qO(?DS,?q_0)q(?DS,?q_)q_pump(?DS,? q_heat_pump)Evaluation(?DS,?evaluation) has_pump(?DS,?pump_type)->sqwrl:select(?DS,?total_cost,? bearing_capacity, ?pump_type,?q_0,?q_,?q_heat_pump,?evaluation 


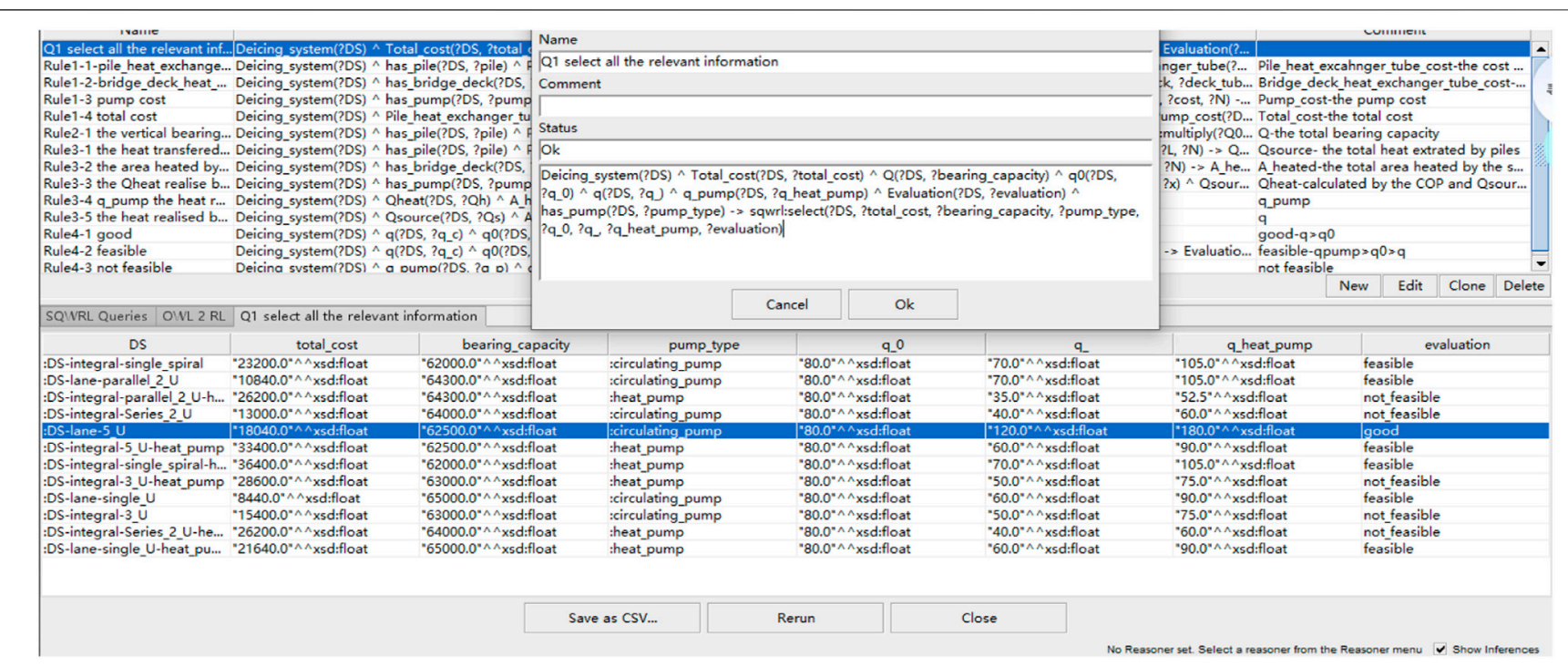

FIGURE 11 | Execution and results of querying Table 7.

TABLE 8 | SQWRL rules to query total cost less than 20,000 RMB.

SQWRL

De-icing_system(?DS)^Total_cost(?DS, ?total_cost)^ Q(?DS, ?bearing_capacity)^qO(?DS, ?q_O)q(?DS,?q_)q_pump(?DS,? q_heat_pump)Evaluation(?DS,?evaluation)has_pump(?DS, ?pump_type)'swrlb:lessThan(?total_cost,20,000)->sqwrl: select(?DS, ?total_cost, ?bearing_capacity, ?pump_type, ?q_0, ?q_, ?q_heat_pump, ?evaluation)

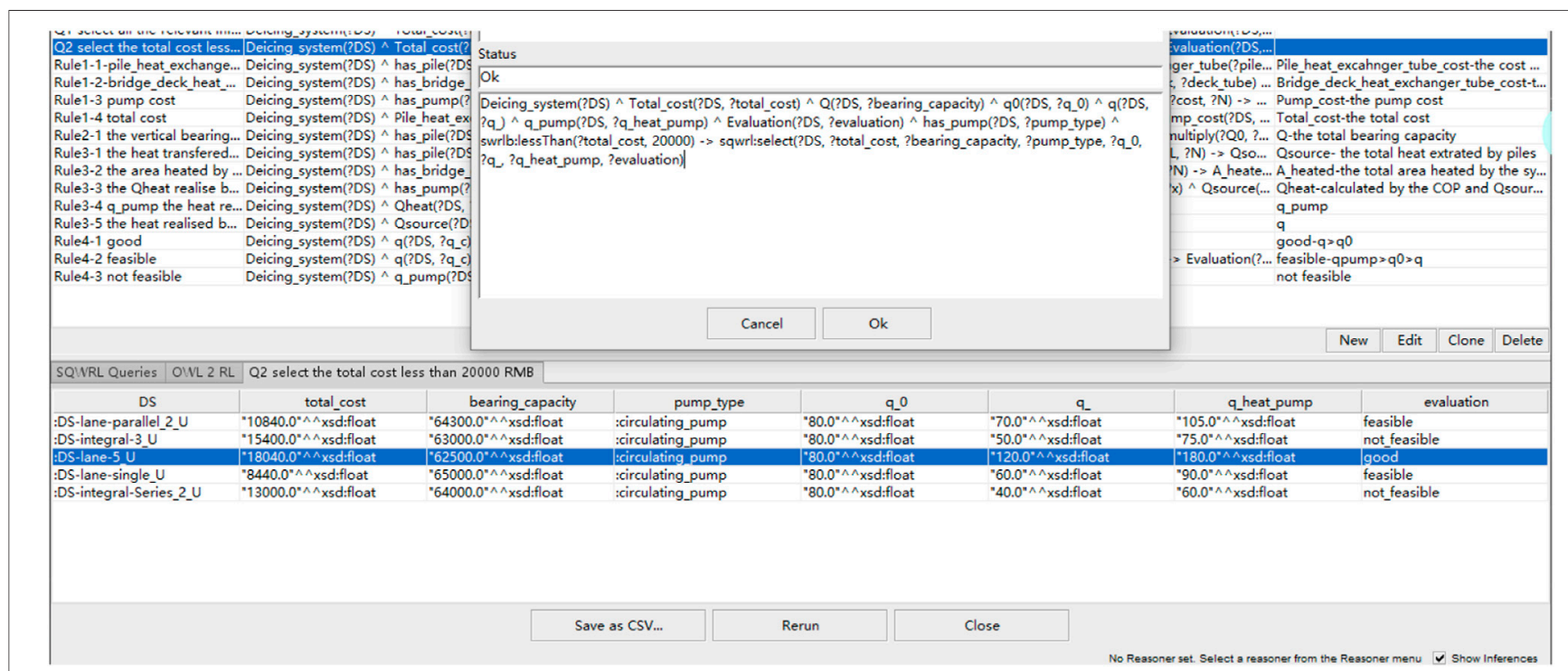

FIGURE 12 | Execution and results of querying Table 8.

transfer tubes will be embedded under the 12 pieces of bridge deck under car lanes. The bridge deck under the bicycle lanes or the sidewalk will not be heated by thermal tubes. Considering the heated area and the volume of circulating water, COP is set to 3 , according to Self et al. (2013). Based on several different types of heat exchangers and heat pumps, 12 design solutions are offered by OntoBDDS. The details of each design solution are presented in Table 2.

Thereafter, OntoBDDS can generate new facts based on the ontology model and the 12 aforementioned designing solutions. The 


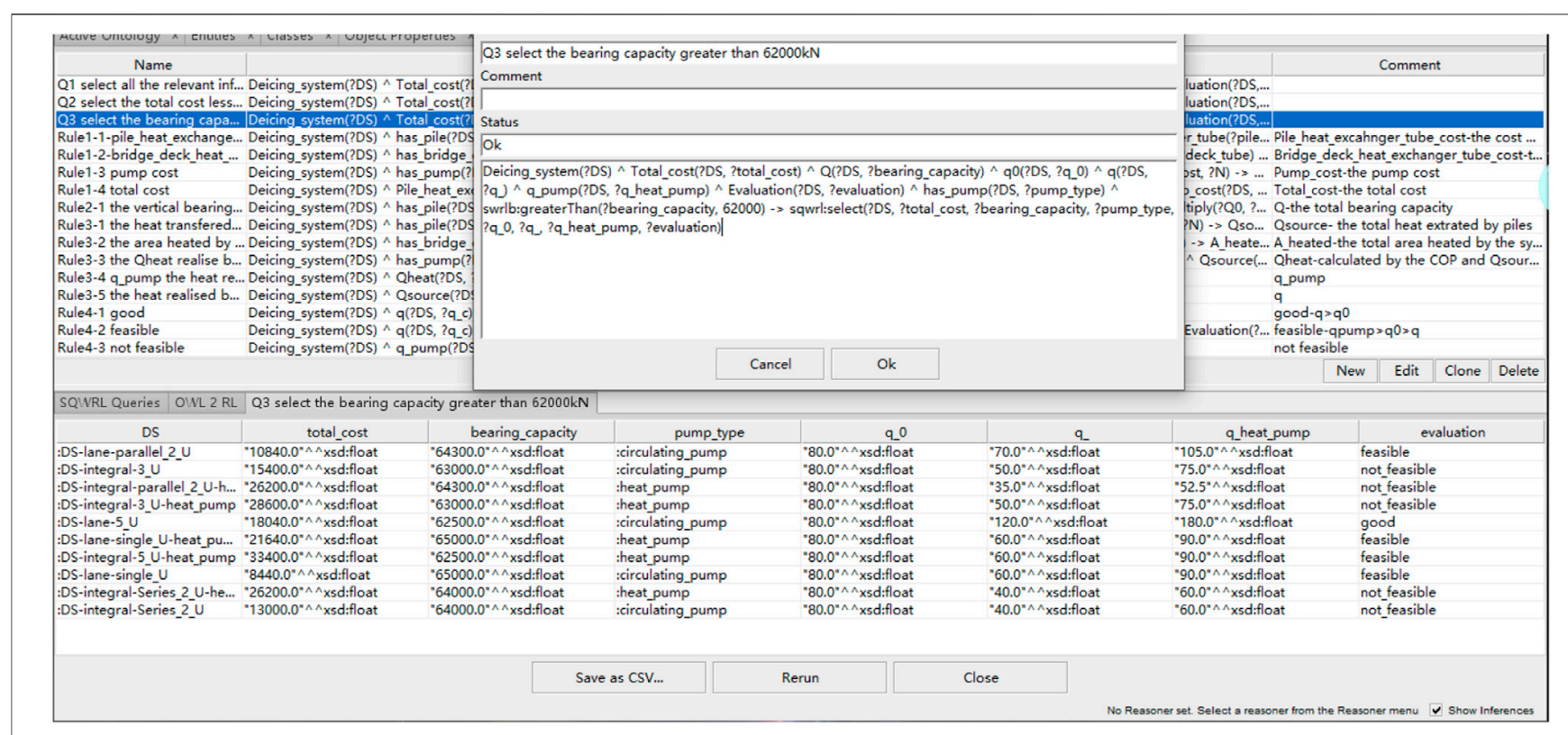

FIGURE 13 | Execution and results of querying Table 9.

TABLE 9 | SQWRL rules to query bearing capacity greater than $62,000 \mathrm{kN}$.

SQWRL

De-icing_system(?DS)Total_cost(?DS,?total_cost)Q(?DS, ?bearing_capacity)'qO(?DS,?q_0) q(?DS,?q_)q_pump(?DS,? q_heat_pump)Evaluation(?DS, ?evaluation)has_pump(?DS, ?pump_type)'swrlb:greaterThan(?bearing_capacity,62000)>sqwrl:select(?DS, ?total_cost, ?bearing_capacity, ?pump_type, ?q_0, ?q_, ?q_heat_pump, ?evaluation)

TABLE 10 | SQWRL rules to query feasible design solutions whose total cost is less than 20,000 RMB.

SQWRL

De-icing_system(?DS)^Total_cost(?DS, ?total_cost)^Q(?DS, ?bearing_capacity)^q0(?DS, ?q_0)^a(?DS, ?q_)^q_pump(?DS, ?q_heat_pump) ^ Evaluation(?DS, ?evaluation) has_pump(?DS,?pump_type)'swrlb:lessThan(?total_cost,20,000)'swrlb: greaterThan (?q_heat_pump,?q_0)->sqwrl:select(?DS, ?total_cost, ?bearing_capacity, ?pump_type, ?q_0, ?q_, ? q_heat_pump,?evaluation)

facts include the cost, heat flux, and bearing capacity among other features of each design solution. Figure $\mathbf{1 0}$ demonstrates the interface after running the ontology model and reasoning rules. The reasoning rules are also presented from Table 3-6. Thereafter, engineers can use a plug-in called SQWRLQueryTAB to inquire the generated facts and make a comparison of each design solution.

\section{Application}

This section demonstrates how engineers can use OntoBDDS to perform inquiry designing solutions of bridge deck deicing system in accordance with specified requirements. The inquires can be conducted through inputting SQWRL commands in the SQWRLTab. For example, the total cost, bearing capacity, and heat flux can be obtained by the command shown in Table 7 and the querying results are illustrated in Figure 11. Engineers can compare each design and make preliminary decisions.
Specialized design requirements can also be easily satisfied by SQWRL querying. Table 8 shows the SQWRL querying command to filter design results with a total cost below 20,000 $\mathrm{RMB}$. The querying results are illustrated in Figure 12. It can be seen that five designs satisfy this requirement and only three are graded as feasible.

Figure 13 illustrates the running results of Table 9, which aims to find design solutions with bearing capacity larger than $62,000 \mathrm{kN}$. It is shown that ten solutions are satisfying this requirement. Furthermore, the bearing capacities of all those filtered design solutions are of the same order of magnitude, which implies that the OntoBDDS can provide reasonable design solutions.

Hear flux and cost are also two major indicators of the deicing system. Table 10 demonstrates the SQWRL command to filter design solutions of a cost less than 20,000 RMB and acceptable heat flux. The querying results are illustrated in Figure 14. It can be seen that there are three acceptable design solutions. The solution with heat pump and 5-U type heat 


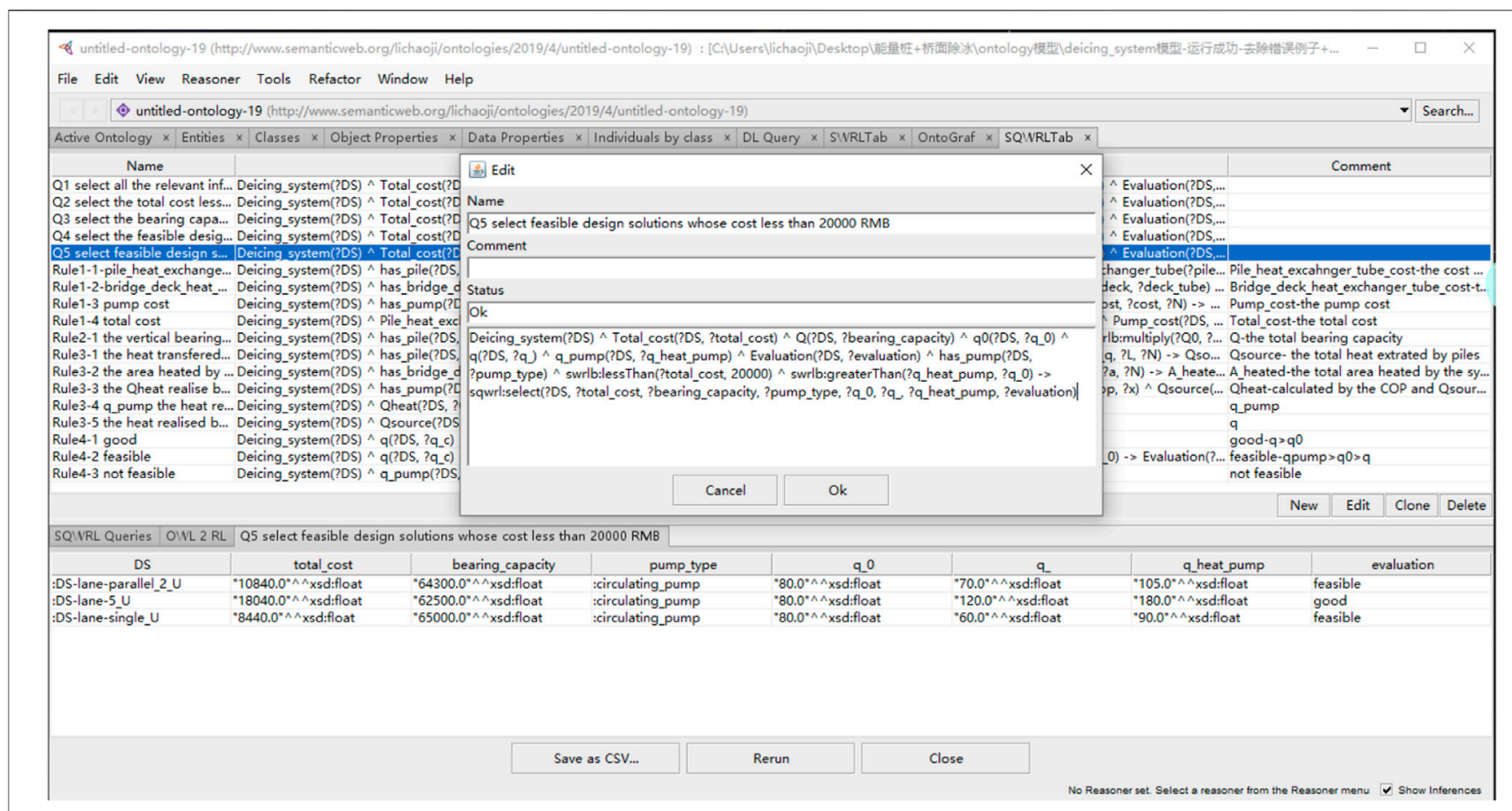

FIGURE 14 | Execution and results of querying Table 10.

transfer tube offers the least cost and highest heat flux and therefore is the optimal solution.

\section{CONCLUSION AND FUTURE WORK}

Based on the ontology modeling method and the SWRL language, this paper establishes an integrated design system for energy pile bridge deck deicing systems. The OntoBDDS system is developed and provides designers with a simple and easy-to-use optimization design tool. The system provides designers with indicators on the economy, heat flux, and safety aspects of the design plan, so that the designer can choose and optimize the plan.

At the same time, this article uses a design example to demonstrate how engineers should use this system to optimize the design of the energy pile bridge deck deicing system when considering different design requirements. The example also shows the feasibility of the system. This ontology model is also developed based on the IFC standard and an existing, verified ontology model. The correctness of its semantics, grammar, and rules have also been verified. At the same time, the example shows how the system can be used when focusing on different design priorities, such as cost, safety, and heat flux to achieve the optimal system configuration and satisfy engineering requirements.

The concept of using OntoBDDS tools and an ontology framework as illustrated in this article can also be applied to other energy pile projects, such as energy tunnels, integrated design of building energy pile systems, etc. In future work, this ontology-based integrated design concept can be extended to all aspects of engineering, and further efforts will be placed on developing knowledge acquisition methods involving more semantic explication (such as during cross-disciplinary interaction in a large-scale numerical analysis). Further development in this area can help basic or cross-domain reasoning in practical scenarios.

\section{DATA AVAILABILITY STATEMENT}

The data used to support the findings of this study are available from the corresponding author upon request.

\section{AUTHOR CONTRIBUTIONS}

PZ, CC, CL, and CZ conceived and designed the research work. PZ, CL, and HL analyzed the data. PZ, CL, and HL prepared original draft. CC and $\mathrm{CZ}$ reviewed and edited the paper. All authors contributed to the article and approved the submitted version.

\section{FUNDING}

This research was funded by the National Natural Science Foundation of China (NSFC), Grant no. 51808092, and United Navigation Foundation of Liaoning Province, Grant no. 2020HYLH-48. 


\section{REFERENCES}

Ahmed, V., Pathmeswaran, R., and Aouad, G. (2007). A Generic Framework for the Development of Standardised Learning Objects within the Discipline of Construction Management. J. Educ. Built Environ. 2, 115-135. doi:10.11120/ jebe.2007.02020115

Amatya, B. L., Soga, K., Bourne-Webb, P. J., Amis, T., and Laloui, L. (2012). Thermo-mechanical Behaviour of Energy Piles. Géotechnique 62, 503-519. doi:10.1680/geot.10.p.116

Balbay, A., and Esen, M. (2010). Experimental Investigation of Using Ground Source Heat Pump System for Snow Melting on Pavements and Bridge Decks. Sci. Res. Essays 5, 3955-3966. doi:10.1029/2009JG001147

Bourne-Webb, P. J., Amatya, B., Soga, K., Amis, T., Davidson, C., and Payne, P. (2009). Energy Pile Test at Lambeth College, London: Geotechnical and Thermodynamic Aspects of Pile Response to Heat Cycles. Géotechnique 59, 237-248. doi:10.1680/geot.2009.59.3.237

Bowers, G. A., and Olgun, C. G. (2015). Experimental Investigation of Bridge Deck Deicing Using Energy Piles. San Antonio, TX: Geotechnical Special Publication, 1628-1637.

Brandl, H. (2006). Energy Foundations and Other Thermo-Active Ground Structures. Géotechnique 56, 81-122. doi:10.1680/geot.2006.56.2.81

Dupray, F., Li, C., and Laloui, L. (2014). Heat-exchanger Piles for the De-icing of Bridges. Acta Geotech. 9, 413-423. doi:10.1007/s11440-014-0307-2

Green, R., Bean, C. A., and Myaeng, S. H. (2002). The Semantics of Relationships. Inf. Sci. Knowledge Manage. 3, 325-327. doi:10.1007/978-94-017-0073-3

GuizzardiGiancarlo, H., Terry, V., Johanna, V., Denny, S., and York (2008). AEON - an Approach to the Automatic Evaluation of Ontologies. Appl. Ontol. 3 (12), 41-62. doi:10.3233/O-2008-0048

Han, C., and Yu, X. (2017). Feasibility of Geothermal Heat Exchanger Pile-Based Bridge Deck Snow Melting System: A Simulation Based Analysis. Renew. Energ. 101, 214-224. doi:10.1016/j.renene.2016.08.062

Horrocks, I., Patel-Schneider, P. F., Boley, H., Tabet, S., Grosof, B., Boley, H., et al. (2004). SWRL: A Semantic Web Rule Language Combining OWL and RuleML. doi:10.1145/988672.988771

Jeong, S., Lim, H., Lee, J. K., and Kim, J. (2014). Thermally Induced Mechanical Response of Energy Piles in Axially Loaded Pile Groups. Appl. Therm. Eng. 71, 608-615. doi:10.1016/j.applthermaleng.2014.07.007

Kong, G., Wu, D., Liu, H., Laloui, L., Cheng, X., and Zhu, X. (2019). Performance of a Geothermal Energy Deicing System for Bridge Deck Using a Pile Heat Exchanger. Int. J. Energ. Res. 43, 596-603. doi:10.1002/er.4266

Laloui, L. (2011). "In-situ Testing of a Heat Exchanger Pile," in Geo-Frontiers 2011: Advances in Geotechnical Engineering - Proceedings of the Geo-Frontiers 2011 Conference, Location Dallas, Texas, March 13-16, 2011 (American Society of Civil Engineers ASCE). doi:10.1061/41165(397)43

Lee, W.-K., Lee, H.-A., Hwang, S.-s., Kim, H., Lim, Y.-H., Hong, Y.-C., et al. (2014). A Time Series Study on the Effects of Cold Temperature on Road Traffic Injuries in Seoul, Korea. Environ. Res. 132, 290-296. doi:10.1016/j.envres.2014.04.019

Liu, X., Rees, S. J., and Spitler, J. D. (2007). Modeling Snow Melting on Heated Pavement Surfaces. Part II: Experimental Validation. Appl. Therm. Eng. 27, 1125-1131. doi:10.1016/j.applthermaleng.2006.07.029

Liu, H., Maghoul, P., Bahari, A., and Kavgic, M. (2018). Feasibility Study of Snow Melting System for Bridge Decks Using Geothermal Energy Piles Integrated with Heat Pump in Canada. Renew. Energ. 136, 1266-1280. doi:10.1016/ j.renene.2018.09.109

Loveridge, F., and Powrie, W. (2013). Pile Heat Exchangers: thermal Behaviour and Interactions. Proc. Inst. Civil Eng. - Geotech. Eng. 166, 178-196. doi:10.1680/ geng. 11.00042

Miyamoto, S., and Takeuchi, M. (2005). Snow-Melting System on Road Using Seasonal Energy Storage Through Foundation Piles for Bridge. Doboku Gakkai Ronbunshu 2005, 51-797. doi:10.2208/jscej.2005.797_51

Morino, K., and Oka, T. (1994). Study on Heat Exchanged in Soil by Circulating Water in a Steel Pile. Energy and Buildings 21, 65-78. doi:10.1016/03787788(94)90017-5

Nagai, N., Miyamoto, S., Tsuda, T., and Yamahata, S. (2009). "Experimental Demonstrations and Optimal Design Conditions of Snow-Melting System Using Geothermal and Solar Energy," in Asme Heat Transfer Summer Conference Collocated with the Interpack09 \& Energy Sustainability Conferences, Location Dallas, Texas, March 13-16, 2011. doi:10.1115/ ht2009-88181

Noy, N. F., and Mcguinness, D. L. (2001). Ontology Development 101: A Guide to Creating Your First Ontology. And San Antonio, TX: Stanford Medical Informatics.

Ozudogru, T. Y., Olgun, C. G., and Arson, C. F. (2015). Analysis of Friction Induced Thermo-Mechanical Stresses on a Heat Exchanger Pile in Isothermal Soil. San Antonio, TX: Geotechnical\&Geological Engineering.

Ren, G., Ding, R., and Li, H. (2019). Building an Ontological Knowledgebase for Bridge Maintenance. Adv. Eng. Softw. 130, 24-40. doi:10.1016/j.advengsoft.2019.02.001

Self, S. J., Reddy, B. V., and Rosen, M. A. (2013). Geothermal Heat Pump Systems: Status Review and Comparison with Other Heating Options. Appl. Energ. 101, 341-348. doi:10.1016/j.apenergy.2012.01.048

Yari, M., and Javani, N. (2010). Performance Assessment of a Horizontal-Coil Geothermal Heat Pump. Int. J. Energ. Res. 31, 288-299. doi:10.1002/er.1230

Yurchyshyna, A., and Zarli, A. (2009). An Ontology-Based Approach for Formalisation and Semantic Organisation of Conformance Requirements in Construction. Automat. Constr. 18, 1084-1098. doi:10.1016/j.autcon.2009.07.008

Zhang, K., and Liao, P.-C. (2015). Ontology of Ground Source Heat Pump. Renew. Sust. Energ. Rev. 49, 51-59. doi:10.1016/j.rser.2015.04.021

Conflict of Interest: The authors declare that the research was conducted in the absence of any commercial or financial relationships that could be construed as a potential conflict of interest.

Publisher's Note: All claims expressed in this article are solely those of the authors and do not necessarily represent those of their affiliated organizations, or those of the publisher, the editors, and the reviewers. Any product that may be evaluated in this article, or claim that may be made by its manufacturer, is not guaranteed or endorsed by the publisher.

Copyright $\odot 2021$ Zhang, Cui, Li, Zhang and Liu. This is an open-access article distributed under the terms of the Creative Commons Attribution License (CC BY). The use, distribution or reproduction in other forums is permitted, provided the original author(s) and the copyright owner(s) are credited and that the original publication in this journal is cited, in accordance with accepted academic practice. No use, distribution or reproduction is permitted which does not comply with these terms. 